\title{
Ocorrência de anticorpos e fatores de risco para infecçáo por Toxoplasma gondii em cáes, nas cidades de Lages e Balneário Camboriú, Santa Catarina, Brasil
}

\author{
Occurrence of antibodies and risk factors for infection for Toxoplasma gondii in dogs \\ in the cities of Lages and Balneário Camboriú, Santa Catarina State, Brazil \\ Anderson B. de Moura ${ }^{1 *}$; Antonio P. de Souza ${ }^{1}$; Amélia A. Sartor ${ }^{1}$; Valdomiro Bellato'; \\ Everton B. Teixeira'; ${ }^{2}$ Greise M. Pisetta ${ }^{2}$; Afonso Heusser Junior ${ }^{3}$ \\ ${ }^{1}$ Departamento de Medicina Veterinária, Centro de Ciências Agroveterinárias - CAV, \\ Universidade do Estado de Santa Catarina - UDESC \\ ${ }^{2}$ Curso de Medicina Veterinária, Centro de Ciências Agroveterinárias - CAV, \\ Universidade do Estado de Santa Catarina - UDESC / Bolsista de Iniciação Científica do PROBIC/UDESC \\ ${ }^{3}$ Mestrado em Ciência Animal, Centro de Ciências Agroveterinárias - CAV, Universidade do Estado de Santa Catarina - UDESC
}

Recebido em 27 de Fevereiro de 2009

Aceito em 7 de Abril de 2009

\section{Resumo}

Com os objetivos de conhecer a ocorrência de anticorpos e identificar fatores de risco para a infecção por Toxoplasma gondii em cães, nas cidades de Lages e Balneário Camboriú, SC, amostras de sangue de 400 cáes domiciliados foram processadas para a detecção de anticorpos contra $T$. gondii pela técnica da imunofluorescência indireta (RIFI). Dados referentes à raça, idade, sexo, tipo de dieta, ambiente, presença de gatos e acesso à rua foram obtidos por meio de questionário. Análise estatística foi realizada (teste de $\chi^{2}$ ). Dos 400 cães, 89 (22,3\%) apresentaram anticorpos contra T. gondii. Dos cães de Lages, 52 (26\%) foram positivos para T. gondii, enquanto os de Balneário Camboriú, 37 (18,5\%) foram sororreagentes. Não foram observadas diferenças estatísticas entre as prevalências de $T$. gondii nos dois municípios. Maior ocorrência de sororreagentes para toxoplasmose foi verificada entre os cães sem raça definida $(P=0,002)$, que tinham acesso à rua $(\mathrm{P}=0,003)$ e que recebiam dieta caseira $(\mathrm{P}=0,028)$. Forte tendência para reagentes ao $T$. gondii foi observada entre os animais adultos, indicando exposição pós-natal ao agente, e entre os cães em contato com felinos.

Palavras-chave: Toxoplasma gondii, Canis familiaris, fatores de risco.

\begin{abstract}
The aim of this study was to identify the occurrence of antibodies and risk factors for infection for Toxoplasma gondii in dogs in the cities of Lages and Balneário Camboriú, Santa Catarina State, Brazil. Blood samples from 400 domiciliated dogs were processed for antibody detection against $T$. gondii by indirect immunofluorescence antibody test (IFAT). The following variables were obtained by questionnaire: breed, age, sex, diet, environment, presence of cats and street access. A Chi-Square test was performed to verify the association between the seroprevalence with the studied variables. From all evaluated dogs, 89 (22.3\%) had antibodies against T. gondii. A total of $52(26 \%)$ and 37 (18.5\%) dogs were positive for T. gondii in Lages and Balneário Camboriú, respectively. No statistical differences were observed on the prevalences of T. gondii between both cities. Greater occurrences of seropositives for toxoplasmosis were observed in mixed-breed $\operatorname{dogs}(\mathrm{P}=0.002)$, who had access to the street $(\mathrm{P}=0.003)$ and received homemade $\operatorname{diet}(\mathrm{P}=0.028)$. A strong trend for seropositivity against $T$. gondii was observed among adult dogs, indicating post-natal exposure, and among those that have previous contact with cats.
\end{abstract}

Keywords: Toxoplasma gondii, Canis familiaris, risk factors.

\footnotetext{
*Autor para correspondência: Anderson B. de Moura

Departamento de Medicina Veterinária, Centro de Ciências Agroveterinárias - CAV,

Universidade do Estado de Santa Catarina - UDESC

Av. Luís de Camóes, 2.090, CEP 88520-000 Lages - SC, Brasil

e-mail:a2abm@cav.udesc.br
} 


\section{Introdução}

A toxoplasmose é uma doença de elevada importância, uma vez que os animais servem de fonte direta ou indireta de infecção para o ser humano, além dos prejuízos causados nos animais de produçáo e/ou de companhia.

Em cães, a toxoplasmose é mais severa em filhotes. Os sinais clínicos mais comuns são: ataxia, diarréia e alteraçôes respiratórias, como dispnéia e tosse que pode evoluir para pneumonia, principalmente em co-infecçóes com o vírus da cinomose canina (DUBEY et al., 2003). Casos de pneumonia causados exclusivamente pelo $T$. gondii foram reportados (CAPEN; COLE, 1966 apud DUBEY, 1993). Miosite (DUBEY, 1993) e desordens neurológicas (MORALES et al., 1995; MINEO et al., 2001; TARLOW et al., 2005) e oculares (ABREU et al., 2002) também têm sido associadas à toxoplasmose canina.

Embora incomum, a forma disseminada da toxoplasmose pode acometer cães sujeitos a condiçóes imunossupressoras, inclusive com manifestaçôes cutâneas da doença (WEBB et al., 2005).

A ingestáo de cistos teciduais, presentes principalmente nas carnes suína e ovina, e/ou de água e alimentos contaminados por oocistos é a forma mais frequente de transmissão na natureza. Mesmo não sendo a principal via de transmissão, a toxoplasmose congênita em cães também pode ocorrer, como relataram Bresciani et al. (1999) e Bresciani (2003) em trabalhos de inoculação experimental do T. gondii em cadelas prenhes.

Quanto ao aspecto zoonótico, mesmo remota, existe a possibilidade de cáes atuarem como vetores mecânicos na disseminaçáo do protozoário (LINDSAY et al., 1997; ETHEREDGE et al., 2004; SCHARES et al., 2005), embora Luo e Lou (2003) não tenham obtido sucesso na detecção do T. gondii em amostras fecais de 26 cães, por meio da reaçâo em cadeia da polimerase (PCR). Uma alternativa para avaliar a disseminaçáo urbana do $T$. gondii é o estudo da soroprevalência em animais que atuam como sentinelas, uma vez que estes estão expostos a riscos similares ao ser humano para a infecção toxoplásmica.

A soropositividade ao $T$. gondii em cáes é relativamente alta em nosso País. A detecção de anticorpos apresenta índices que variam de 20,8\% (ROMANELLI et al., 2007) até 76,4\% (CAÑÓN-FRANCO et al., 2004), de acordo com a região estudada e/ou técnica diagnóstica empregada. A ausência de dados sobre o status sorológico para toxoplasmose em cáes, nas cidades de Lages e Balneário Camboriú, no Estado de Santa Catarina, bem como os possíveis fatores de risco para a infecção, justificaram a execuçâo do presente estudo.

\section{Material e Métodos}

O estudo foi desenvolvido em dois municípios do Estado de Santa Catarina. Lages, situada no planalto catarinense ( $27^{\circ} 48^{\prime} 57^{\prime \prime} \mathrm{S}$ e $50^{\circ} 20^{\prime} 33^{\prime \prime} \mathrm{O}$ ), a $916 \mathrm{~m}$ de altitude, com temperatura média de $14,3^{\circ} \mathrm{C}$; e Balneário Camboriú, localizado no litoral catarinense ( $26^{\circ} 59^{\prime} 27^{\prime \prime} \mathrm{S}$ e $48^{\circ} 38^{\prime} 06^{\prime \prime} \mathrm{O}$ ), a $2 \mathrm{~m}$ de altitude e com temperatura média anual de $20,1^{\circ} \mathrm{C}$.

Entre agosto de 2006 e julho de 2007, amostras de sangue de 400 cães domiciliados (200 em cada cidade), clinicamente sadios, obtidas de forma aleatória, por venopunção, foram remetidas ao
Laboratório de Parasitologia e Doenças Parasitárias do CAV/UDESC para obtenção do soro que foi estocado a $-20^{\circ} \mathrm{C}$ até o processamento para a detecção de anticorpos contra $T$. gondii pela técnica de Reação de Imunofluorescência Indireta (RIFI). Dados referentes à raça, idade, sexo, tipo de dieta, ambiente, presença de felinos e acesso à rua foram obtidos por meio de questionário aplicado aos proprietários.

A RIFI para a pesquisa de anticorpos contra $T$. gondii foi realizada de acordo com Camargo (1964). Taquizoítos da cepa RH de T. gondii (SABIN, 1941) foram utilizados como antígeno. Os soros dos cães foram diluídos em solução salina tamponada ( $\mathrm{pH} 7,2)$ e titulados de 1:16 até 1:4096. Utilizaram-se soros controles positivo e negativo, previamente testados pela RIFI, obtidos junto ao Laboratório de Medicina Veterinária Preventiva da Universidade Estadual de Londrina, para comparação. Foram considerados positivos os animais que apresentaram título de anticorpos $\geq 16$ (SILVA et al., 2002). Os resultados obtidos foram anotados e a análise estatística foi realizada por meio do Teste de Qui-quadrado $\left(\chi^{2}\right)$, com nível de significância de 5\%, para correlacionar a soropositividade dos animais com possíveis fatores de risco.

\section{Resultados e Discussáo}

Das 400 amostras de sangue colhidas, 89 (22,3\%) apresentaram anticorpos contra $T$. gondii, enquanto 311 (77,7\%) foram negativas. Dos câes de Lages, 52 (26\%) foram positivos para $T$. gondii, enquanto os de Balneário Camboriú, 37 (18,5\%) foram sororreagentes. Os títulos obtidos podem ser visualizados na Tabela 1. Esse é o primeiro relato acerca da ocorrência de anticorpos e dos fatores de risco para a infecção canina pelo T. gondii em Santa Catarina. Por se tratar de um coccídio cosmopolita, T. gondii é encontrado nas mais distintas regiôes geográficas, podendo apresentar índices de prevalência bastante variáveis.

Cabral et al. (1998), em Uberlândia, MG, observaram que 52,7\% de cães aparentemente saudáveis eram sororreagentes para $T$. gondii, por meio da técnica de hemaglutinação indireta, na titulação $\geq 64$. No Mato Grosso e Rondônia, estudos encontraram, respectivamente, 35\% (GRÖSZ, et al., 2002) e 76,4\% (CAÑÓN-FRANCO et al., 2004) de cães reagentes para T. gondii pela RIFI. Esses autores utilizaram a diluição $\geq 1: 16$ como ponto de corte. No Estado de São Paulo, Cassol et al. (2005), por meio da RIFI ( $\geq 16)$, e Dubey et al. (2007a), pela técnica modificada de aglutinação (MAT) e "cut off" de 1:20, observaram 36 e $35,8 \%$ dos cães avaliados reagentes ao T. gondii, respectivamente. Na Paraíba, Azevedo et al. (2005) identificaram $45,1 \%$ dos cáes soropositivos para toxoplasmose, por meio da RIFI e ponto de corte $\geq 1: 16$. Em Guarapuava, PR, Romanelli et al. (2007) detectaram 20,8\% dos cấes sororreagentes (RIFI com "cut off" de 1:16). Em Jaboticabal, São Paulo, Domingues et al. (1998), utilizando as técnicas de ensaio imunoenzimático (ELISA) e RIFI ( $\geq 40$ ), relataram a ocorrência, respectivamente, de 62,5 e 46,01\% de cáes reagentes ao $T$. gondii. Com exceção do estudo realizado por Romanelli et al. (2007), que encontraram prevalência de $20,8 \%$, os demais trabalhos apresentaram valores de soropositividade superiores aos do presente estudo, mesmo naqueles em que o ponto de corte utilizado foi maior que 1:16. 
Tabela 1. Recíproca dos títulos de anticorpos contra Toxoplasma gondii, obtidos pela Reação de Imunofluorescência Indireta (RIFI), em soro de cães das cidades de Lages e de Balneário Camboriú, SC, 2007.

\begin{tabular}{llllllc}
\hline \multicolumn{1}{c}{ Título / Cidade } & \multicolumn{1}{c}{ Negativo } & $\mathbf{1 : 1 6}$ & $\mathbf{1 : 6 4}$ & $\mathbf{1 : 2 5 6}$ & $\mathbf{1 : 1 0 2 4}$ & Total \\
\hline Lages & $148(74 \%)$ & $27(13,5 \%)$ & $12(6 \%)$ & $10(5 \%)$ & $03(1,5 \%)$ & $200(100 \%)$ \\
Balneário Camboriú & $163(81,5 \%)$ & $09(4,5 \%)$ & $11(5,5 \%)$ & $14(7 \%)$ & $03(1,5 \%)$ & $200(100 \%)$ \\
Total & $311(77,8 \%)$ & $36(9 \%)$ & $23(5,8 \%)$ & $24(6 \%)$ & $06(1,5 \%)$ & $400(100 \%)$ \\
\hline
\end{tabular}

Tabela 2. Frequência de cães positivos (RIFI $\geq 16$ ) para Toxoplasma gondii nas cidades de Lages e Balneário Camboriú, Estado de Santa Catarina, 2007. Por variável analisada e total.

\begin{tabular}{|c|c|c|c|c|c|c|c|}
\hline \multirow{2}{*}{ Variável } & \multicolumn{2}{|c|}{ Animais } & \multicolumn{2}{|c|}{ Positivos $^{1}$} & \multicolumn{2}{|c|}{ Positivos $^{2}$} & \multirow{2}{*}{$\mathbf{P}$} \\
\hline & $\mathbf{n}$ & $\%$ & $\mathrm{n}$ & $\%$ & $\mathbf{n}$ & $\%$ & \\
\hline \multicolumn{8}{|l|}{ Raça } \\
\hline SRD & 250 & 62,5 & 68 & 27,2 & 68 & 76,4 & \multirow{2}{*}{0,002} \\
\hline $\mathrm{RD}$ & 150 & 37,5 & 21 & 14,0 & 21 & 23,6 & \\
\hline \multicolumn{8}{|l|}{ Sexo } \\
\hline Macho & 223 & 55,8 & 47 & 21,1 & 47 & 52,8 & \multirow{2}{*}{0,526} \\
\hline Fêmea & 177 & 44,2 & 42 & 23,7 & 42 & 47,2 & \\
\hline \multicolumn{8}{|l|}{ Idade } \\
\hline 0 a $12 \mathrm{M}$ & 125 & 31,2 & 22 & 17,6 & 22 & 24,7 & \multirow{2}{*}{0,132} \\
\hline $13 \mathrm{ou}+\mathrm{M}$ & 275 & 68,8 & 67 & 24,4 & 67 & 75,3 & \\
\hline \multicolumn{8}{|l|}{ Dieta } \\
\hline Ração & 131 & 32,8 & 23 & 17,6 & 23 & 25,8 & \multirow{3}{*}{0,028} \\
\hline Caseira & 113 & 28,2 & 35 & 31,0 & 35 & 39,3 & \\
\hline Mista & 156 & 39 & 31 & 19,9 & 31 & 34,9 & \\
\hline \multicolumn{8}{|l|}{ Ambiente } \\
\hline Piso total & 64 & 16 & 10 & 15,6 & 10 & 11,2 & \multirow{2}{*}{0,164} \\
\hline Grama / Terra & 336 & 84 & 79 & 23,5 & 79 & 88,8 & \\
\hline \multicolumn{8}{|l|}{ Presença de felinos } \\
\hline Sim & 112 & 28 & 34 & 30,6 & 34 & 38,2 & \multirow{2}{*}{0,015} \\
\hline Não & 288 & 72 & 55 & 19,1 & 55 & 61,8 & \\
\hline \multicolumn{8}{|l|}{ Acesso à rua } \\
\hline Sim & 206 & 51,5 & 58 & 28,2 & 58 & 65,2 & \multirow{2}{*}{0,003} \\
\hline Não & 194 & 48,5 & 31 & 16,0 & 31 & 34,8 & \\
\hline Total & 400 & 100 & 89 & & 89 & 100 & \\
\hline
\end{tabular}

SRD: Sem Raça Definida; RD: Raça Definida; Positivos ${ }^{1}$ : Relação entre os animais positivos dentro de uma variável sobre o total de animais daquela variável; Positivos $^{2}$ : Relação entre os animais positivos dentro de uma variável sobre o total de animais positivos; P: Nível descritivo do teste de $\chi^{2}$.

Wanha et al. (2005), na Áustria, por meio da RIFI com ponto de corte na diluição 1:50; Öncel et al. (2007), na Turquia, também pela RIFI, mas com ponto de corte na diluição 1:64; Dubey et al. (2007b), na Colômbia, pela MAT com "cut off" $\geq 1: 20$; e Dubey et al. (2007c), na cidade de Durango, México, também por meio da MAT, mas com ponto de corte 1:25, relatam $25,51,3,16,8$ e $51,5 \%$ dos cães sororreagentes ao protozoário, respectivamente.

Os resultados do teste de $\chi^{2}$, aplicado para avaliar a influência das diversas variáveis analisadas na frequência de anticorpos contra T. gondii podem ser observados na Tabela 2 .

Houve diferença estatística significante entre os cáes reagentes ao T. gondii que não tinham raça definida $(\mathrm{P}=0,002)$ e aqueles com acesso à rua $(\mathrm{P}=0,003)$. Os resultados aqui observados podem ser consequência do tipo de manejo a que esses animais sem raça definida (SRD) e com acesso à rua são submetidos, provavelmente mais expostos às fontes de infecção, como roedores e oocistos eliminados por felinos (MINEO et al., 2004). Langoni et al. (2006) também verificaram maior ocorrência de soropositivos entre cães SRD. Entretanto, Bresciani et al. (2007) e Romanelli et al. (2007) não encontraram diferença significativa entre cães reagentes a T. gondii em relação ao padrão racial.

O tipo de dieta apresentou diferença estatística significante $(\mathrm{P}=0,028)$. A maioria dos animais positivos $(66 / 89$ ou $74,2 \%)$ recebeu alimentação caseira ou mista. Assim, uma das principais formas infectantes desse coccídio (cistos) para cães (GERMANO et al., 1985) poderia ter ocorrido mais frequentemente na dieta desses animais, contribuindo para uma maior prevalência dessa parasitose entre esses cães. Ao contrário, Cañón-Franco et al. (2004) e Salb et al. (2008) não encontraram correlação entre dieta e soroprevalência canina para T. gondii. 
Embora a variável idade não apresentasse diferença estatística, a análise dos dados demonstra forte tendência a uma maior ocorrência de reagentes entre os animais adultos, uma vez que, entre os positivos, $75,3 \%$ dos animais tinham idade $\geq 13$ meses. Guimarães et al. (1992), em Belo Horizonte, MG, observaram que $62 \%$ dos cáes positivos para $T$. gondii tinham idade superior a cinco anos. Cañón-Franco et al. (2004), em Rondônia, relataram que a prevalência de $T$. gondii tende a aumentar com a idade dos cães, uma vez que animais mais velhos apresentam maior probabilidade de entrar em contato com as fontes de infecção (meio e/ou dieta). O mesmo foi observado por Azevedo et al. (2005) e Langoni et al. (2006).

Quando analisada a presença de felinos em contato com os cáes, a análise estatística demonstra que a convivência com gatos náo significa necessariamente um fator de risco para a infecção por $T$. gondii nesses cães $(\mathrm{P}=0,015)$. $\mathrm{O}$ mesmo foi observado por Bresciani et al. (2007). Este resultado pode indicar que gatos não estejam eliminando oocistos nas suas fezes ou, ainda, que os oocistos não seriam a principal fonte de infecção deste coccídio para estes cães. Entretanto, uma interpretação mais cautelosa evidencia que os cães que mantiveram contato com felinos apresentaram positividade de 30,6 ante 19,1\% daqueles sem esse contato, revelando a influência da coabitação entre as duas espécies na ocorrência de anticorpos contra $T$. gondii. Do mesmo modo, Azevedo et al. (2005) observaram que a coabitação com gatos representa um fator de risco para a soropositividade de cães ao $T$. gondii.

$\mathrm{O}$ tipo de piso em que os animais eram mantidos, assim como o sexo, não apresentou correlação com a infecção toxoplásmica dos cães no presente estudo.

\section{Conclusóes}

A taxa de infecção por T. gondii entre os cães de Lages e os de Balneário Camboriú foi de 26 e 18,5\%, respectivamente, não apresentando diferença em relação à regiáo analisada.

Uma maior ocorrência de sororreagentes para $T$. gondii foi verificada entre os cães sem raça definida, que recebiam comida caseira e com acesso à rua. Grande tendência de soropositividade ao T. gondii foi observada entre os animais adultos, indicando exposição pós-natal ao agente, e entre aqueles que tiveram contato com gatos.

\section{Agradecimentos}

Ao Prof. Dr. Odilon Vidotto e à Técnica Dra. Elizabete R. M. Marana, do Laboratório de Protozoologia, Departamento de Medicina Veterinária Preventiva, Centro de Ciências Agrárias da Universidade Estadual de Londrina, pela cessão das lâminas com antígeno de $T$. gondii.

\section{Referências}

ABREU, C. B. et al. Toxoplasmose ocular em cáes jovens inoculados com Toxoplasma gondii. Ciência Rural, v. 32, n. 5, p. 807-812, 2002.
AZEVEDO, S. S. et al. Seroepidemiology of Toxoplasma gondii and Neospora caninum in dogs from the state of Paraíba, Northeast region of Brazil. Research in Veterinary Science, v. 79, n. 1, p. 51-56, 2005.

BRESCIANI, K. D. S. Estudo da reinfecçáo por Toxoplasma gondii (Nicolle \& Manceaux, 1909) em cadelas gestantes naturalmente infectadas. Jaboticabal, 2003. 132 p. Tese (Doutorado em Medicina Veterinária Preventiva) - Universidade Estadual Paulista - UNESP.

BRESCIANI, K. D. S. et al. Experimental toxoplasmosis in pregnant bitches. Veterinary Parasitology, v. 86, n. 2, p. 143-145, 1999.

BRESCIANI, K. D. S. et al. Ocorrência de anticorpos contra Neospora caninum e Toxoplasma gondii e estudo de fatores de risco em cães de Araçatuba-SP. Ars Veterinaria, v. 23, n. 1, p. 40-46, 2007.

CABRAL, D. D. et al. Frequency of anti-Toxoplasma gondii antibodies in apparently healthy dogs of the city of Uberlândia - MG. Revista Brasileira de Parasitologia Veterinária, v. 7, n. 2, p. 87-90, 1998.

CAMARGO, M. E. Improvided technique of indirect immunofluorescence for serological diagnosis of toxoplasmosis. Revista do Instituto de Medicina Tropical de Sáo Paulo, v. 6, n. 3, p. 117-118, 1964.

CAÑÓN-FRANCO, W. A. et al. Ocurrence of anti-Toxoplasma gondii antibodies in dogs in the urban area of Monte Negro, Rondonia, Brazil. Veterinary Research Communications, v. 28, n. 2, p. 113-118, 2004.

CASSOL, D. M. S. et al. Pesquisa de anticorpos contra Neospora caninum e Toxoplasma gondii em bovinos leiteiros, cáes e humanos da Região Nordeste do Estado de Sáo Paulo. A Hora Veterinária, v. 24, n. 145, p. 23-26, 2005.

DOMINGUES, L. M. et al. Canine toxoplasmosis: a comparative evaluation of the detection of anti-Toxoplasma gondii antibodies by the immunoenzymatic assay (ELISA) and the indirect immunofluorescence reaction (IIF). Revista Brasileira de Parasitologia Veterinária, v. 7, n. 2, p. 79-85, 1998 .

DUBEY, J. P. Toxoplasma, Neospora, Sarcocystis and other tissue cystforming of human and animals. In: KREIER, J. P. Parasitic protozoa. 2 ed. San Diego: Academic Press, 1993. p. 1-157.

DUBEY, J. P.; ROSS, A. D.; FRITZ, D. Clinical Toxoplasma gondii, Hammondia heydorni, and Sarcocystis spp. infections in dogs. Parassitologia, v. 45, n. 3-4, p. 141-146, 2003.

DUBEY, J. P. et al. Diverse and atypical genotypes identified in Toxoplasma gondii from dogs in São Paulo, Brazil. Journal of Parasitology, v. 93, n. 1, p. 60-64, 2007a.

DUBEY, J. P. et al. Prevalence of Toxoplasma gondii in dogs from Colombia, South America and genetic characterization of $T$. gondii isolates. Veterinary Parasitology, v. 145, n. 1-2, p. 45-50, $2007 \mathrm{~b}$.

DUBEY, J. P. et al. Neospora caninum and Toxoplasma gondii antibodies in dogs from Durango City, Mexico. Journal of Parasitology, v. 93, n. 5 , p. $1033-1035,2007$ c.

ETHEREDGE, G. D. et al. The roles of cats and dogs in the transmission of Toxoplasma infection in Kuna and Embera children in eastern Panamá. Revista Panamericana de Salud Publica, v. 16, n. 3, p. 176-186, 2004.

GERMANO, P. M. L.; ERBOLATO, E. B.; ISHIZUKA, M. M. Estudo sorológico da toxoplasmose canina, pela prova de imunofluorescência indireta, na cidade de Campinas, 1981. Revista da Faculdade de Medicina Veterinária e Zootecnia, v. 22, n. 1, p. 53-58, 1985. 
GRÖSZ, L. C. B. et al. Inquérito soroepidemiológico da toxoplasmose canina no perímetro urbano de Cuiabá, Estado do Mato Grosso. Revista Brasileira de Medicina Veterinária, v. 24, n. 3, p. 118-121, 2002.

GUIMARÁES, A. M. et al. Frequência de anticorpos anti-Toxoplasma gondii em cães de Belo Horizonte, Minas Gerais. Arquivo Brasileiro de Medicina Veterinária e Zootecnia, v. 44, n. 1, p. 67-68, 1992.

LANGONI, H. et al. Serological profile of anti-Toxoplasma gondii antibodies in apparently healthy dogs of the city of Botucatu, São Paulo State, Brazil. Journal of Venomous Animals and Toxins Including Tropical Diseases, v. 12, n. 1, p. 142-148, 2006.

LINDSAY, D. S. et al. Mechanical transmission of Toxoplasma gondii oocysts by dogs. Veterinary Parasitology, v. 73, n. 1-2, p. 27-33, 1997.

LUO, H. M.; LOU, L. H. Detection of Toxoplasma gondii in human blood and animal excrements by nested-polymerase chain reaction. Chinese Journal of Veterinary Medicine, v. 39, n. 9, p. 12-14, 2003.

MINEO, T. W. P. et al. Detection of IgG antibodies to Neospora caninum and Toxoplasma gondii in dogs examined in a veterinary hospital from Brazil. Veterinary Parasitology, v. 98, n. 4, p. 239-245, 2001.

MINEO, T. W. P. et al. Toxoplasma gondii and Neospora caninum serological status of different canine populations from Uberlândia, Minas Gerais. Arquivo Brasileiro de Medicina Veterinária e Zootecnia, v. 56, n. 3, p. 414-417, 2004.

MORALES, J. A. et al. Neosporosis and toxoplasmosis: associated paralysis in dogs in Costa Rica. Applied Parasitology, v. 36, n. 3, p. 179-184, 1995.

ÖNCEL, T. et al. Determination of seropositivity for Toxoplasma gondii in stray dogs in Istanbul, Turkey. Revue de Medecine Veterinaire, v. 158, n. 5, p. 223-228, 2007.
ROMANELLI, P. R. et al. Prevalence of Neospora caninum and Toxoplasma gondii in sheep and dogs from Guarapuava farms, Paraná State, Brazil. Research in Veterinary Science, v. 82, n. 2, p. 202-207, 2007.

SABIN, A. B. Toxoplasmic encephalitis in children. Journal of the American Medical Association, v. 116, n. 9, p. 801-807, 1941.

SALB, A. L. et al. Dogs as sources and sentinels of parasites in humans and wildlife, northern Canada. Emerging Infectious Diseases, v. 14 n. 1, p. 60-63, 2008.

SCHARES, G. et al. Oocysts of Neospora caninum, Hammondia heydorni, Toxoplasma gondii and Hammondia hammondi in faeces collected from dogs in Germany. International Journal for Parasitology, v. 35, n. 14, p. 1525-1537, 2005.

SILVA, N. M. et al. Optimisation of Cut-off titres in Toxoplasma gondii specific ELISA and IFAT in dog sera using immunoreactivity to SAG-1 antigen as a molecular marker of infection. Veterinary Journal, v. 163 , n. 1, p. 94-98, 2002.

TARLOW, J. M. et al. Emergency presentations of 4 dogs with suspected neurologic toxoplasmosis. Journal of Veterinary Emergency and Critical Care, v. 15, n. 2, p. 119-127, 2005.

WANHA, K. et al. Prevalence of antibodies against Neospora caninum and Toxoplasma gondii in dogs and foxes in Austria. Veterinary Parasitology, v. 128, n. 3-4, p. 189-193, 2005.

WEBB, J. A. et al. Cutaneous manifestations of disseminated toxoplasmosis in an immunosuppressed dog. Journal of the American Animal Hospital Association, v. 41, n. 3, p. 198-202, 2005. 